\title{
A Agência Federal de Redes da República Federal da Alemanha
}

The German Federal Network Agency

Patrick Leonardo de Faria e Silva*

\begin{abstract}
Resumo
O propósito do artigo é o de analisar a Agência Federal de Redes (Bundesnetzagentur) - a sucessora da antiga Autoridade Regulatória de Correios e Telecomunicações (RegTP) - na República Federal da Alemanha. A primeira parte do artigo descreve o histórico de evolução das telecomunicações na Alemanha. A segunda parte se dedica a explicar as razões para a criação da Bundesnetzagentur, suas funções e sua estrutura.
\end{abstract}

\section{Abstract}

The purpose of this paper is to analyze the Federal Network Agency (Bundesnetzagentur), the new name for the Regulatory Authority for Telecommunications and Posts (RegTP) in the Federal Republic of Germany. In the first part of the article will be described the historical evolution of the telecommunication's Law in Germany. The second part is devoted to explaining the reasons for the creation of the Bundesnetzagentur, its tasks and its organization.

\section{Introdução}

O setor de telecomunicações da República Federal da Alemanha vivenciou, nas últimas duas décadas, significativas transformações, entre elas o surgimento, em julho de 2005, da "Agência Federal de Redes" (Bundesnetzagentur $)^{* *}$, autoridade regulatória que sucedeu o antigo "Órgão Regulador para Telecomunicações e Serviços Postais" (Regulierungsbehörde für Telekommunikation und Post-RegTP).

O presente artigo tem por escopo o estudo da Bundesnetzagentur. Para tanto, na primeira parte do trabalho, descreve-se a evolução histórica do

*Mestre em Direito pela Ludwig-Maximilians-Universität München. Especialista em regulação de telecomunicações pela Universidade de Brasília. Membro pesquisador do Grupo de Estudo em Direito das Telecomunicações da UnB (GETEL/UnB). Diretor da Seccional do Distrito Federal da Associação Brasileira de Direito de Informática e Telecomunicações (ABDI). Especialista em regulação de serviços públicos de telecomunicações na Agência Nacional de Telecomunicações.

**Tradução livre dos termos em alemão. 
direito das telecomunicações na Alemanha, que é tradicionalmente dividida pela doutrina em cinco fases - antes de 1949, de 1949 a 1989 e Primeira, Segunda e Terceira Reformas Postais ${ }^{1}$. A segunda parte, por sua vez, é dedicada ao exame do surgimento da Agência Federal de Redes, suas atribuições e estrutura, com especial ênfase nos motivos que resultaram na conformação desta nova autoridade regulatória, bem como no impacto que sua criação representou para o setor de telecomunicações na Alemanha.

\section{Evolução Histórica do Direito das Telecomunicações na Alemanha}

Antes de se abordar especificamente a criação, atribuições e estrutura da Agência Federal de Redes, interessante traçar uma visão geral do ambiente político-institucional e legal em meio ao qual surgiu referido órgão regulador, o que remete a breve escorço histórico.

\section{Antes de 1949}

Uma das primeiras regulamentações no direito alemão a respeito de telecomunicações que se tem notícia é a que constou na "Constituição do Reich Alemão" (Verfassung des Deutschen Reiches), a chamada "Constituição de Paulskirchen", de 1849, a qual atribuía à administração do Reich, em seu parágrafo 44, inciso 1, a implantação de linhas telegráficas e a utilização das já existentes (por meio de indenização aos seus proprietários ou através de desapropriação). ${ }^{2}$

Posteriormente, a "Constituição da Liga Setentrional Alemã" (Verfassung des Norddeutschen Bundes), de 1867, definia no seu artigo 4,

${ }^{1}$ Koenig, Christian; Loetz, Sascha; Neumann, Andreas. Telekommunikationsrecht. Vol. I, $1^{\text {a }}$ ed., Heidelberg: Editora Recht und Wirtschaft, 2004, p. 93-101. Chen, Yung-chih, Die Liberalisierung der Telekommunikationsmärkte in Deutschland und das neue Konzept der Regulierung. Vol. 1, $1^{\text {a }}$ ed., Berlin: Editora Rhombos, 2002, p. 31-86.

${ }^{2}$ Verfassung des Norddeutschen Bundes/1867: “Art. 4. Der Beaufsichtigung Seitens des Bundes und der Gesetzgebung desselben unterliegen die nachstehenden Angelegenheiten: (...) 10. Das Post- und Telegraphenwesen".

Revista de Direito, Estado e Telecomunicações, v. 1, n. 1, p. 161-180 (2009)

DOI: https://doi.org/10.26512/lstr.vli1.21742 
inciso 10, como competência da Federação, a produção de legislação sobre serviços postais e telegráficos e a respectiva fiscalização. ${ }^{3}$

Referida competência foi reproduzida, em 1871, na "Constituição do Reich" (Reichsverfassung), também no seu artigo 4, inciso 10, com ressalva em relação aos serviços postais e telegráficos dos estados do sul da Alemanha, Bayern e Württemberg. ${ }^{4}$

Com as primeiras transmissões de voz via cabo, ocorridas a partir de 1861, seguidas da invenção do telefone e sua patente em 1876, iniciou-se, em 1877, a exploração dos serviços de telefonia, a qual ficou exclusivamente a cargo da "Administração Postal e Telegráfica do Reich" (Reichs-Post-und-Telegraphen-Verwaltung), sendo que, em 1889, a justiça do Reich classifica o telefone como uma espécie de telegrafia. ${ }^{5}$

Posteriormente, no ano de 1892, edita-se a "Lei de Telégrafos" (Telegraphengesetz), primeira lei no direito das telecomunicações germânico que se dedicou exclusivamente à regulamentação das telecomunicações, abrangendo serviços telegráficos e telefônicos. Anote-se que referida lei aborda pioneiramente a inviolabilidade do sigilo telegráfico e telefônico. ${ }^{6}$

Com a promulgação da "Constituição de Weimar" (Weimarer Reichsverfassung), em 1919, a competência para legislação sobre serviços postais e telegráficos continuou atribuída com exclusividade ao então ente superior do Estado - o Reich. ${ }^{7}$

Da mesma forma, a exploração dos serviços postais e telegráficos, incluindo os telefônicos (desta vez, previstos expressamente em categoria

${ }^{3}$ Verfassung des Norddeutschen Bundes/1867: "Art. 4. Der Beaufsichtigung Seitens des Bundes und der Gesetzgebung desselben unterliegen die nachstehenden Angelegenheiten: (...) 10. Das Post- und Telegraphenwesen".

${ }^{4}$ Reichsverfassung des Jahres 1871: "Art. 4. Der Beaufsichtigung seitens des Reichs und der Gesetzgebung desselben unterliegen die nachstehenden Angelegenheiten: (...) 10. Das Post- und Telegraphenwesen, jedoch in Bayern und Württemberg nur unter Maßgabe der Bestimmung im Artikel 52".

${ }^{5}$ Koenig, Christian; Loetz, Sascha; Neumann, Andreas. Telekommunikationsrecht. Vol. I, $1^{\text {a }}$ ed., Heidelberg: Editora Recht und Wirtschaft, 2004, p. 90.

${ }^{6}$ Koenig, Christian; Loetz, Sascha; Neumann, Andreas. Telekommunikationsrecht. Vol. I, $1^{a}$ ed., Heidelberg: Editora Recht und Wirtschaft, 2004, p. 90.

${ }^{7}$ Weimarer Reichsverfassung/1919: "Art. 6. Das Reich hat die ausschließliche Gesetzgebung über: (...) 7. das Post- und Telegraphenwesen einschließlich des Fernsprechwesens". 
autônoma), permaneceu ao encargo privativo do Reich. ${ }^{8}$ Ainda na "Constituição de Weimar", a proteção ao sigilo telefônico foi elevada a preceito constitucional. ${ }^{9}$

Em 1924, entrou em vigor a "Lei de Finanças Postais do Reich" (Reichpostfinanzgesetz), a qual transforma a instituição acima mencionada, “Administração Postal e Telegráfica do Reich”, responsável pela exploração dos serviços telefônicos, em "Serviços Postais Alemães do Reich" (Deutsche Reichpost), empresa pública independente de capital próprio, vinculada apenas juridicamente, e não financeiramente, ao Reich $^{10}$ (o que se perdeu, em 1934, com a tomada de poder pelos nacional-socialistas). Em 1928, a "Lei Telegráfica" foi revogada pela "Lei sobre Equipamentos de Telecomunicações" (Gesetz über Fernmeldeanlagen), que continuava a prever o monopólio do Reich na exploração dos serviços de telecomunicações. ${ }^{11}$

Após o término da II Guerra Mundial, em 1945, as Redes de Telecomunicações dos "Serviços Postais Alemães do Reich" foram paralisadas e seus bens confiscados. ${ }^{12}$

\section{De 1949 a 1989}

Em 1948, no território ocupado por americanos e britânicos, uma nova e provisória administração para os serviços postais e telefônicos é criada, o "Serviços Postais Alemães do Território Aliado" (Deutsche Post im Vereiningten Wirtschaftsgebiet).

Após a II Guerra Mundial, surge, em 1949, a República Federal da Alemanha, com a promulgação da "Lei Fundamental da República Federal

${ }^{8}$ Weimarer Reichsverfassung/1919: "Art. 88 (1) Das Post- und Telegraphenwesen samt dem Fernsprechwesen ist ausschließlich Sache des Reichs".

${ }^{9}$ Weimarer Reichsverfassung/1919: "Art. 117. Das Briefgeheimnis sowie das Post-, Telegraphen- und Fernsprechgeheimnis sind unverletzlich. Ausnahmen können nur durch Reichsgesetz zugelassen warden".

${ }^{10} \mathrm{Chen}$, Yung-chih. Die Liberalisierung der Telekommunikationsmärkte in Deutschland und das neue Konzept der Regulierung. Vol. 1, $1^{\text {a }}$ ed., Berlin: Editora Rhombos, 2002, p. 31.

${ }^{11}$ Koenig, Christian; Loetz, Sascha; Neumann, Andreas. Telekommunikationsrecht. Vol. I, $1^{\text {a }}$ ed., Heidelberg: Editora Recht und Wirtschaft, 2004, p. 91.

${ }^{12}$ Koenig, Christian; Loetz, Sascha; Neumann, Andreas. Telekommunikationsrecht. Vol. I, ${ }^{a}$ ed., Heidelberg: Editora Recht und Wirtschaft, 2004, p. 91.

Revista de Direito, Estado e Telecomunicações, v. 1, n. 1, p. 161-180 (2009)

DOI: https://doi.org/10.26512/lstr.vli1.21742 
da Alemanha (Grundgesetz für die Bundesrepublik Deutschland). Boa parte dos dispositivos sobre direito das telecomunicações constantes da "Constituição de Weimar" foi reproduzida nessa nova Carta, os quais somente vieram a ser modificados no final do século $\mathrm{XX}$, como se verá adiante.

Uma das características principais da "Lei Fundamental" foi o cuidado do legislador constituinte na disposição sobre os direitos fundamentais, entre eles o sigilo das comunicações previsto no art. 10, cuja tutela foi consideravelmente reforçada, isto como conseqüência das conhecidas reiteradas violações que sofreram durante o regime nacional-socialista. ${ }^{13}$

O artigo 73 da citada Constituição estabelecia competência exclusiva da Federação para legislação sobre serviços postais e telecomunicações. ${ }^{14}$ Já o artigo 87, parágrafo primeiro, dispunha que o "Serviço Federal Postal Alemão" (Deutsche Bundespost), como substituto dos "Serviços Postais Alemães do Reich", passava a fazer parte da administração direta federal. ${ }^{15}$

No plano infraconstitucional, continuava a viger a "Lei sobre Equipamentos de Telecomunicações" (Gesetz über Fernmeldeanlagen), com ligeiras modificações que não tangenciaram a atribuição de monopólio da exploração dos serviços de telecomunicações, agora não mais ao Reich, mas à Federação.

Com o passar dos anos, os serviços de telecomunicações, no entanto, iam se tornando cada vez mais insuficientes no atendimento das necessidades da população. Além disso, o "Serviço Federal Postal Alemão" passou a acumular vultosos prejuízos, dando ensejo, na metade da década de sessenta, às primeiras discussões a respeito de uma possível reforma do setor, o que veio efetivamente a ocorrer somente na década de oitenta, com a edição da Lei de Estruturação dos Serviços Postais" (Poststrukturgesetz). ${ }^{16}$

${ }^{13}$ Koenig, Christian; Loetz, Sascha; Neumann, Andreas. Telekommunikationsrecht. Vol. I, $1^{\text {a }}$ ed., Heidelberg: Editora Recht und Wirtschaft, 2004, p. 93.

${ }^{14}$ Grundgesetz für die Bundesrepublik Deutschland Artikel: 73: "Der Bund hat die ausschließliche Gesetzgebung über: (...) 7. das Postwesen und die Telekommunikation".

${ }^{15}$ Chen, Yung-chih. Die Liberalisierung der Telekommunikationsmärkte in Deutschland und das neue Konzept der Regulierung. Vol. 1, $1^{\text {a }}$ ed., Editora Berlin: Rhombos, 2002, p. 31.

${ }^{16}$ Koenig, Christian; Loetz, Sascha; Neumann, Andreas. Telekommunikationsrecht. Vol. I, $1^{\text {a }}$ ed., Heidelberg: Editora Recht und Wirtschaft, 2004, p. 94. 


\section{A Primeira Reforma Postal}

A aludida lei inaugurou, em 1989, o que se veio a denominar na Alemanha de "Primeira Reforma Postal" (Postreform I) motivada, além dos fatores acima declinados, por uma nova concepção econômica do setor de telecomunicações, em que a idéia de que seus serviços se submetiam a um monopólio natural foi perdendo forças. Tal concepção se engendrou, em especial, devido aos avanços tecnológicos da época, além das pressões políticas advindas da Comunidade Européia, que passou a editar diretrizes relacionadas à necessidade de se quebrar monopólios, mais especificamente, monopólios relacionados com a comercialização de aparelhos telefônicos. ${ }^{17}$

$\mathrm{O}$ ponto central da referida "Primeira Reforma Postal" cingiu-se à separação das atividades políticas em relação às atividades empresariais e operacionais do "Serviço Federal Postal Alemão", ficando as primeiras a mando do "Ministério dos Correios e das Telecomunicações" (Bundesministerium für Post und Telekommunikation - BMPT) e as últimas a cargo do "Serviço Federal Postal Alemão", transformado, pela lei, em três empresas públicas: "Serviço Federal Postal Alemão - Serviço Postal" (Deutsche Bundespost POSTDIENST), "Serviço Federal Postal Alemão Banco Postal" (Deutsche Bundespost POSTBANK) e "Serviço Federal Postal Alemão - Telecomunicações" (Deutsche Bundespost TELEKOM). ${ }^{18}$ Assim, agilizou-se, em larga escala, a eficiência dos serviços de telecomunicações, na medida em que estes passaram a se submeter a princípios empresariais (como perseguição de lucros, rigoroso equilíbrio entre despesa e receita etc.), ainda que na permanência do regime público. ${ }^{19}$

Por fim, o quase secular monopólio dos terminais telefônicos foi quebrado, além de se iniciar, paulatinamente, a abertura à iniciativa privada

${ }^{17}$ Koenig, Christian; Loetz, Sascha; Neumann, Andreas. Telekommunikationsrecht. Vol. I, ${ }^{a}$ ed., Heidelberg: Editora Recht und Wirtschaft, 2004, p. 94.

${ }^{18}$ Knieps, Günter. Competition, Regulation and Privatisation: The Railroads and Telecommunications Network Industries in Germany. Freiburg: Discussion Paper Institut für Verkehrswissenschaft und Regionalpolitik N. 104, 2004, p. 6.

${ }^{19}$ Chen, Yung-chih. Die Liberalisierung der Telekommunikationsmärkte in Deutschland und das neue Konzept der Regulierung. Vol. 1, $1^{\text {a }}$ ed., Berlin: Editora Rhombos, 2002, p. 36-37. 
da exploração de alguns ramos específicos, como, por exemplo, o de telefonia móvel. ${ }^{20}$

\section{A Segunda Reforma Postal}

Em 1994, veio a lume a "Segunda Reforma Postal" (Postreform II), provocada por uma Emenda Constitucional que retirou o artigo 87 e inseriu, em seu lugar, os artigos $87-\mathrm{f}^{21}$ e $143-\mathrm{b}^{22}$, que passaram a permitir a submissão dos serviços de telecomunicações ao direito privado, dispondo sobre a privatização do "Serviço Federal Postal Alemão". As três empresas criadas pela "Primeira Reforma Postal" ("Serviço Federal Postal Alemão Serviço Postal, Banco Postal e Telecomunicações") foram transmudadas em sociedades anônimas, que, pela própria natureza, permitiam a venda de ações a particulares. ${ }^{23}$ Após a queda do muro de Berlim, fazia-se indispensável o aporte de capital privado para possibilitar a instalação/modernização dos serviços de telecomunicações nos territórios anexados da antiga Alemanha Oriental. ${ }^{24}$

${ }^{20}$ Xavier, Patrick; Ypsilanti, Dimitri. Regulatory Reform In Germany. Paris, Publicações OECD, 2004, p. 8.

${ }^{21}$ Grundgesetz für die Bundesrepublik Deutschland/1949: "Artikel 87-f (1) Nach Maßgabe eines Bundesgesetzes, das der Zustimmung des Bundesrates bedarf, gewährleistet der Bund im Bereich des Postwesens und der Telekommunikation flächendeckend angemessene und ausreichende Dienstleistungen. Dienstleistungen im Sinne des Absatzes 1 werden als privatwirtschaftliche Tätigkeiten durch die aus dem Sondervermögen Deutsche Bundespost hervorgegangenen Unternehmen und durch andere private Anbieter erbracht".

${ }^{22}$ Grundgesetz für die Bundesrepublik Deutschland/1949: "Artikel 143b (1) Das Sondervermögen Deutsche Bundespost wird nach Maßgabe eines Bundesgesetzes in Unternehmen privater Rechtsform umgewandelt (...) (2) Die vor der Umwandlung bestehenden ausschließlichen Rechte des Bundes können durch Bundesgesetz für eine Übergangszeit den aus der Deutschen Bundespost POSTDIENST und der Deutschen Bundespost TELEKOM hervorgegangenen Unternehmen verliehen werden".

${ }^{23}$ Knieps, Günter. Competition, Regulation and Privatisation: The Railroads and Telecommunications Network Industries in Germany. Freiburg: Discussion Paper Institut für Verkehrswissenschaft und Regionalpolitik No. 104, 2004, p. 6.

${ }^{24}$ Koenig, Christian; Loetz, Sascha; Neumann, Andreas. Telekommunikationsrecht. Vol. I, $1^{\text {a }}$ ed., Heidelberg: Editora Recht und Wirtschaft, 2004, p. 95. 


\section{A Terceira Reforma Postal}

Dois anos depois, uma terceira reforma se fez necessária, ocorrendo a denominada "Terceira Reforma Postal" (Postreform III), em função da promulgação da "Lei das Telecomunicações (Telekommunikationsgesetz), aprovada em $1^{\circ}$ de agosto de 1996, que revogou, em grande parte, a ("Lei sobre Equipamentos de Telecomunicações"), de 1928.

Referida lei é composta de partes que tratam, entre outras, sobre: regras gerais; normas regulatórias econômicas; normas regulatórias não econômicas; normas técnicas; e, em especial, uma parte (parágrafos 66 a 84) que versa sobre o "Órgão Regulador para Telecomunicações e Serviços Postais" (Regulierungsbehörde für Telekommunikation und Post-RegTP), que entrou em operação no dia $1^{\circ}$ de janeiro de 1998.

Mediante essa nova lei, o legislador se comprometeu, definitivamente, com a abertura do mercado dos serviços das telecomunicações, implementando, de uma vez por todas, a concorrência no setor. Isto pode ser verificado já no parágrafo $1^{\circ}$ da lei, o qual prevê:

Telekommunikationsgesetz/1996: § 1. Zweck dieses Gesetzes ist es, durch Regulierung im Bereich der Telekommunikation den Wettbewerb zu fördern und flächendeckend angemessene und ausreichende Dienstleistungen zu gewährleisten sowie eine Frequenzordnung festzulegen. ("O objetivo desta lei é, por meio de regulação no setor de telecomunicações, promover a concorrência, garantir de modo amplo serviços adequados e suficientes e fixar um regulamento de frequências").

Importante registrar, também, que no parágrafo $2^{\circ}$ da lei são definidos seis objetivos regulatórios, entre eles, a garantia do interesse dos usuários, a garantia de uma competição isonômica e funcional e o provimento de serviços de telecomunicações a preços acessíveis. ${ }^{25}$

${ }^{25}$ Telekommunikationsgesetz/1996: " $\$ 2$ Ziele der Regulierung sind: (1) die Wahrung der Interessen der Nutzer auf dem Gebiet der Telekommunikation und des Funkwesens sowie die Wahrung des Fernmeldegeheimnisses (2) die Sicherstellung eines chancengleichen und funktionsfähigen Wettbewerbs, auch in der Fläche, auf den Märkten der Telekommunikation (3) die Sicherstellung einer flächendeckenden Grundversorgung mit Telekommunikationsdienstleistungen (Universaldienstleistungen) zu erschwinglichen Preisen (4) die Förderung von Telekommunikationsdiensten bei öffentlichen Einrichtungen (5) die Sicherstellung einer effizienten und störungsfreien Nutzung von Frequenzen, auch unter Revista de Direito, Estado e Telecomunicações, v. 1, n. 1, p. 161-180 (2009)

DOI: https://doi.org/10.26512/lstr.vli1.21742 
Nos anos que se seguiram a sua edição, a "Lei das Telecomunicações" sofreu algumas modificações de menor porte, sendo que, em 2004, em razão de diversas diretrizes lançadas pela Comunidade Europeia direcionadas ao setor de telecomunicações e conflitantes com a citada lei, veio à baila o impasse: bastaria a "Lei das Telecomunicações" ser apenas emendada ou um novo marco regulatório se fazia imprescindível? ${ }^{26}$

Após um conturbado processo legislativo, foi sancionada a nova "Lei das Telecomunicações" (Telekommunikationsgesetz), conhecida por TKG 2004, que ab-rogou a antiga "Lei das Telecomunicações", de 1996.

Referido diploma legal se encontra em plena vigência, representando hoje, na Alemanha, o estatuto legal que disciplina os serviços de telecomunicações.

\section{Do RegTP à Bundesnetzagentur}

Regulierungsbehörde für Telekommunikation und Post - RegTP ("Órgão Regulador para Telecomunicações e Serviços Postais”). Este foi, durante quase oito anos, o nome do ente responsável pela regulação dos setores de telecomunicações e serviços postais na República Federal da Alemanha.

Com sede em Bonn, e escritórios regionais localizados em várias cidades da Federação, o RegTP, Autoridade Superior da Administração Federal, vinculada ao "Ministério da Economia e da Tecnologia", (Bundesministerium für Wirtschaft und Technologie) teve sua instituição prevista com a edição da "Lei das Telecomunicações", aprovada em $1^{\circ}$ de agosto de $1996 .^{27}$

O RegTP substituiu o "Ministério Federal dos Correios e das Telecomunicações" e o "Escritório Federal para os Correios e Telecomunicações" (Bundesamt für Post und Telekommunikation - BAPT), ambos órgãos da Administração Federal com atribuições relacionadas aos

Berücksichtigung der Belange des Rundfunks (6) die Wahrung der Interessen der öffentlichen Sicherheit".

${ }^{26}$ Picot/Arnold. Das Telekommunikationsgesetz auf dem Prïfstand. Vol. I, $1^{\text {a }}$ ed. Berlin: Editora Springer, 2004, Prefácio.

${ }^{27} \S 66$ (1) Zur Wahrnehmung der sich aus diesem Gesetz und anderen Gesetzen ergebenden Aufgaben wird die Regulierungsbehörde für Telekommunikation und Post als Bundesoberbehörde im Geschäftsbereich des Bundesministeriums für Wirtschaft und Technologie mit Sitz in Bonn errichtet. 
setores de telecomunicações e de serviços postais antes da Terceira Reforma Postal. Sua operação se iniciou em $1^{\circ}$ de janeiro de 1998, tendo, entre outras funções, no que se refere ao setor de telecomunicações, a promoção da competição, a outorga de licenças, o gerenciamento de radiofrequiência e de numeração, o controle de práticas anticompetitivas, a regulação de preços e tarifas das operadoras com poder de mercado significativo e o monitoramento da interconexão, do acesso às redes e das obrigações de serviço universal. ${ }^{28}$

Em 13 de julho de 2005, por meio da "Lei Sobre a Agência Federal de Redes para Eletricidade, Gás, Telecomunicações, Correios e Ferrovias" (Gesetz über die Bundesnetzagentur für Elektrizität, Gas, Telekommunikation, Post und Eisenbahnen), aprovada como "artigo $2^{\mathrm{o}}$ " (Artikel 2) de um extenso diploma normativo que inovou o Direito Energético na Alemanha, a "Segunda Lei para Nova Regulamentação do Direito Energético Econômico" (Zweites Gesetz zur Neuregelung des Energiewirtschaftsrechts), o RegTP foi renomeado, passando a se chamar "Agência Federal de Redes para Eletricidade, Gás, Telecomunicações, Correios e Ferrovias" (Bundesnetzagentur für Elektrizität, Gas, Telekommunikation, Post und Eisenbahnen) ou, simplesmente, Bundesnetzagentur, tendo também suas atribuições ampliadas, tornando-se responsável pela regulação dos setores de eletricidade, gás e, a partir de 01 de janeiro de 2006, de ferrovias:

Gesetz über die Bundesnetzagentur für Elektrizität, Gas, Telekommunikation, Post und Eisenbahnen/2005: "§1. Die (...) Regulierungsbehörde für Telekommunikation und Post" wird in "Bundesnetzagentur für Elektrizität, Gas, Telekommunikation, Post und Eisenbahnen" (Bundesnetzagentur) umbenannt". ("O órgão Regulador para Telecomunicações e Serviços Postais será renomeado Agência Federal de Redes para Eletricidade, Gás, Telecomunicações, Correios e Ferrovias").

\section{Razões para a criação da Bundesnetzagentur}

À primeira vista, parece muito estranho que o tradicional órgão regulador de telecomunicações e serviços postais se torne, "da noite para o dia", também competente para o controle de mercado de infraestruturas tão

${ }^{28}$ Xavier, Patrick; Ypsilanti, Dimitri. Regulatory Reform in Germany. Paris, Publicações OECD, 2004, p. 14. 
distintas, quais sejam, eletricidade, gás e ferrovias, relacionadas, as duas primeiras, à produção de energia e, a última, ao provimento de transportes.

Sabe-se que telecomunicações e serviços postais são áreas afetas à comunicação e, talvez, por isso, observando-se a evolução histórica do direito das telecomunicações na Alemanha, compreenda-se por que o controle estatal sobre elas, de maneira geral, ocorreu sempre de forma conjunta, fosse por meio da edição de leis que tratavam de ambas as matérias, fosse através da criação de órgãos da Administração responsáveis pelo monitoramento dos dois setores.

Assim, natural que esse controle do Estado, após um processo de abertura de seus mercados para exploração pela iniciativa privada, continuasse a ser exercido pela mesma autoridade, caso uma viesse a ser criada, o que acabou acontecendo com o RegTP.

Com efeito, surge o questionamento sobre o motivo ou motivos que levaram a esta tão estranha e recente transformação.

Para responder essa pergunta, é necessário que se faça uma avaliação, ainda que superficial, do setor energético na Alemanha, cuja evolução nos últimos anos foi o grande motivador para criação desta nova agência. Ou seja, as razões que levaram o RegTP a se transformar em Bundesnetzagentur não se encontram no setor de telecomunicações, tampouco no de serviços postais. Uma crise interna na Alemanha nos segmentos de eletricidade e gás, somada ${ }^{29}$ à edição de diretivas da União Europeia $^{30}$, que obrigaram cada país membro, se ainda não o tivesse feito, a criar um órgão regulador setorial para as referidas infraestruturas, foram os fatores responsáveis por tal mudança.

A exemplo do ocorrido nas telecomunicações, o setor energético também passou por um processo de liberalização na Alemanha. Em abril de 1998, em cumprimento às diretivas comunitárias n. 1996/92/CE e n. 1998/30/CE relacionadas, entre outros aspectos, à produção e à distribuição

${ }^{29}$ Deutsche Welle. Monopólio encarece energia na Alemanha. Bonn: Deutsche Welle, 15.09.2004. [on line] Disponível na internet via WWW.URL: http://www.dwworld.de/dw/article/0,2144,1328713,00.html (consultado em 26/02/2009).

${ }^{30}$ Prevezanos, Klaudia. Sinal verde para maior concorrência. Bonn: Deutsche Welle, 04.09.2003. [on line] Disponível na internet via WWW.URL: http://www.dwworld.de/dw/article/0,2144,962672,00.html (consultado em 26/02/2009).

Revista de Direito, Estado e Telecomunicações, v. 1, n. 1, p. 161-180 (2009) 
de eletricidade e gás, respectivamente, e que determinaram a abertura destes mercados na Europa, foi editada a "Lei da Economia Energética" (Energiewirtschaftsgesetz).

Entre os objetivos dessa norma, estavam a introdução da competição e os consequentes benefícios advindos dela, principalmente, a diminuição das tarifas, tanto para o consumo residencial como para o abastecimento comercial e industrial, sem se olvidar da proteção ao meio ambiente, tema de grande relevância internacional. ${ }^{31}$

Todavia, no conjunto de inovações trazidas pela "Lei da Economia Energética", não estava prevista a criação de um órgão regulador setorial, como aconteceu, expressamente, com o RegTP no setor de telecomunicações, através do $§ 66$ da "Lei das Telecomunicações", de 1996.

Em um primeiro momento, vigendo a "Lei da Economia Energética", as tarifas de consumo de eletricidade e gás baixaram. Contudo, com o decorrer do tempo, essa situação não se sustentou, tendo em vista que, entre outros fatores, a falta de um controle estatal mais rigoroso, fruto da ausência de um órgão regulador setorial, levou a uma série de fusões e aquisições de empresas que resultaram em uma concentração de mercado, revertendo, desta forma, a inicial tendência de redução de preços. Tal fato levou a Alemanha a ocupar um posto não muito confortável na Europa, qual seja, a de país cujas tarifas de energia estavam entre as mais altas, causando grande insatisfação da sociedade e afetando diretamente o seu parque industrial, comprometendo, por sua vez, o seu crescimento econômico.

O monopólio desses conglomerados energéticos se deu principalmente sobre as redes de transmissão, forçando as empresas menores a pagar taxas equivalentes a quase um terço do valor da energia que vendem para poderem distribuir sua produção. ${ }^{32}$

Somada a essa realidade, em junho de 2003, foram sancionadas as diretivas comunitárias n. 2003/54/CE e n. 2003/55/CE, trazendo inovações

${ }^{31} \S 1$ Zweck des Gesetzes ist eine möglichst sichere, preisgünstige und umweltverträgliche leitungsgebundene Versorgung mit Elektrizität und Gas im Interesse der Allgemeinheit.

${ }^{32}$ Deutsche Welle. Monopólio encarece energia na Alemanha. Bonn: Deutsche Welle, 15.09.2004. [on line] Disponível na internet via WWW.URL: http://www.dwworld.de/dw/article/0,2144,1328713,00.html (consultado em 26/02/2009).

Revista de Direito, Estado e Telecomunicações, v. 1, n. 1, p. 161-180 (2009)

DOI: https://doi.org/10.26512/lstr.v1i1.21742 
para os setores elétrico e de gás, respectivamente, que conduziram a Alemanha a uma revisão da sua legislação de energia.

Com isso, após calorosas discussões nas duas casas do Congresso, Bundestag (equivalente à Câmara de Deputados) e Bundesrat (equivalente ao Senado), em julho de 2005, foi aprovado um extenso diploma normativo que pode ser considerado um novo marco regulatório energético na Alemanha, a "Segunda Lei para Nova Regulamentação do Direito Econômico Energético" (Zweites Gesetz zur Neuregelung des Energiewirtschaftsrechts), que trouxe como "artigo $1^{\text {o" }}$ (Artikel 1), a nova "Lei da Economia Energética, conhecida por EnWG - 2005, esta sim, prevendo, expressamente, a subordinação do setor de energia a um regime de regulação, no qual fosse garantida uma competição eficiente e justa. ${ }^{33}$

Durante o processo legislativo, decidiu-se que tal função deveria ser assumida pelo próprio RegTP, dado o curto período de tempo para implementação das diretrizes comunitárias n. 54 e n. 55, passando este órgão a ser denominado "Órgão Regulador Federal para Eletricidade, Gás, Telecomunicações e Correios"34 (Bundesregulierungsbehörde für Elektrizität, Gas, Telekommunikation und Post ou REGTP - sigla com letras maiúsculas). ${ }^{35}$

Todavia, face à edição da "Terceira Lei para Modificação das Normas Ferroviárias" (Dritten Gesetz zur Änderung eisenbahnrechtlicher Vorschriften), que, entre outras determinações, definiu que o controle do acesso à infra-estrutura de ferrovias também deveria ser realizado sob a batuta de um órgão regulador, optou-se por estender ainda mais as já previstas ampliações de competências do RegTP.

Desta forma, o original órgão regulador de telecomunicações e serviços postais, de acordo com a "Lei Sobre a Agência Federal de Redes

${ }^{33} \S 1$ (2) Die Regulierung der Elektrizitäts- und Gasversorgungsnetze dient den Zielen der Sicherstellung eines wirksamen und unverfälschten Wettbewerbs bei der Versorgung mit Elektrizität und Gas und der Sicherung eines langfristig angelegten leistungsfähigen.

${ }^{34}$ Prevezanos, Klaudia. Sinal verde para maior concorrência. Bonn: Deutsche Welle, 04.09.2003. [on line] Disponível na internet via WWW.URL: http://www.dwworld.de/dw/article/0,2144,962672,00.html (consultado em 26/02/2009).

${ }^{35}$ Brunekreeft, Gert; Tweleman, Sven. Regulation, Competition and Investment in the German Eletricity Market: RegTP or REGTP. Cambridge: Cambridge Working Papers in Economics, 2004, p. 1-2. 
para Eletricidade, Gás, Telecomunicações, Correios e Ferrovias" aprovada como "artigo 20" da Segunda Lei para Nova Regulamentação do Direito Energético Econômico", passou a ser denominado Bundesnetzagentur ${ }^{36}$, tornando-se responsável pela regulação das mencionadas infraestruturas.

A idéia central da transformação do RegTP em BundesnetzAgentur foi aproveitar a estrutura e a experiência adquirida pelo RegTP nos seus quase oito anos de existência e aplicá-la no monitoramento de outras áreas que possuem desafios regulatórios semelhantes, a saber: acesso à rede, bottlenecks, limites de capacidade, recursos escassos, entre outros.

Assim, em que pese serem eletricidade, gás, telecomunicações, serviços postais e ferrovias infraestruturas bem distintas umas das outras, algumas em maior grau, outras em menor, todas elas consistem em indústrias de rede e a experiência, isto é, os sucessos e os insucessos adquiridos na regulação de um setor, podem ser usados na regulação de outros. ${ }^{37}$

\section{Atribuições da Bundesnetzagentur}

A "Lei Fundamental da República Federal da Alemanha" (Grundgesetz für die Bundesrepublik Deutschland), de 1949, prevê que a Federação, além de ter competência legislativa exclusiva sobre temas afetos a telecomunicações ${ }^{38}$, também é responsável, no plano administrativo, pela execução de atribuições relacionadas ao setor. ${ }^{39}$

Tal responsabilidade é dividida entre o "Ministério da Economia e da Tecnologia" (Bundesministerium für Wirtschaft und Technologie), e a Bundesnetzagentur.

${ }^{36} \$ 54$ (1) Die Aufgaben der Regulierungsbehörde nehmen die Bundesnetzagentur für Elektrizität, Gas, Telekommunikation, Post und Eisenbahnen (Bundesnetzagentur).

${ }^{37}$ Ofcomwatch. To be or not RegTP. London: Ofcomwatch, 01.08.2005.[on line] Disponível na internet via WWW.URL: http://www.ofcomwatch.co.uk/2005/08/tobe-or-not-regtp (consultado em 26/02/2009).

${ }^{38} \mathrm{GG} / 1949$ : “Art 73. Der Bund hat die ausschließliche Gesetzgebung über: (...) 7. (...) die Telekommunikation".

${ }^{39} \mathrm{GG} / 49$ : "Art 87. (2) (...) Hoheitsaufgaben im Bereich des Postwesens und der Telekommunikation werden in bundeseigener Verwaltung ausgeführt".

Revista de Direito, Estado e Telecomunicações, v. 1, n. 1, p. 161-180 (2009)

DOI: https://doi.org/10.26512/lstr.v1i1.21742 
O "Ministério da Economia e da Tecnologia" é o órgão superior da Administração Federal ao qual a Bundesnetzagentur está vinculada. ${ }^{40}$ Entre as suas atribuições está a edição e a atualização de princípios e diretrizes para as políticas de telecomunicações do governo federal, a elaboração de propostas para mudanças do marco regulatório do setor de telecomunicações, como as que ocorreram com edição da nova "Lei das Telecomunicações", de 2004, e o tratamento de temas relacionados a organismos europeus e internacionais de telecomunicações. ${ }^{41}$

A Bundesnetzagentur, por sua vez, é o órgão regulador do setor ${ }^{42} \mathrm{e}$ seu objetivo principal é aplicar a "Lei de Telecomunicações", de 2004, e seus respectivos regulamentos. No exercício dessa função, inclui-se a promoção da competição, a outorga de licenças, o gerenciamento de radiofreqüência e de numeração, o controle de práticas anticompetitivas, a regulação de preços e tarifas das operadoras com poder de mercado significativo e o monitoramento da interconexão, do acesso às redes e das obrigações de serviço universal. ${ }^{43}$

Os poderes que a Bundesnetzagentur possui para fazer cumprir suas atribuições incluem direitos de informação e investigação, podendo inspecionar negócios e dados das operadoras. As determinações da Agência não podem ser modificadas por autoridade administrativa superior, ou seja, pelo "Ministério da Economia e da Tecnologia", e as ações judiciais iniciadas contra a Bundesnetzagentur devem ser levadas diretamente às Cortes Administrativas. ${ }^{44}$

${ }^{40}$ Gesetz über die Bundesnetzagentur für Elektrizität, Gas, Telekommunikation, Post und Eisenbahnen/2005: “\$1(...) Sie ist eine (...)Bundesoberbehörde im Geschäftsbereich des Bundesministeriums für Wirtschaft und Arbeit (...)”.

${ }^{41}$ Xavier, Patrick; Ypsilanti, Dimitri. Regulatory Reform in Germany. Paris, Publicações OECD, 2004, p. 13.

${ }^{42}$ Gesetz über die Bundesnetzagentur für Elektrizität, Gas, Telekommunikation, Post und Eisenbahnen/2005: " $\$ 2$ Die Bundesnetzagentur ist auf den Gebieten (...) (2) des Telekommunikationsrechts (...)".

${ }^{43}$ Bundesnetzagentur. Aufgaben der Bundesnetzagentur. Bonn: Bundesnetzagentur. [on line] Disponível na internet via WWW.URL: http://www.bundesnetzagentur.de/enid/b9886b3b7b3ff01401b8069b523d1f28,0/Ueb er die Agentur/Aufgaben 30.html (consultado em 26/02/2009).

${ }^{44}$ Bundesnetzagentur. Status der Bundesnetzagentur. Bonn: Bundesnetzagentur. [on line] Disponível na internet via WWW.URL: 


\section{Estrutura da Bundesnetzagentur}

A Agência é dirigida por um presidente e dois vices, nomeados pelo Governo Federal, indicados pelo Presidente da República Federal da Alemanha, de acordo com proposta do "Conselho Consultivo" (Beirat). O presidente e seus vices representam a agência judicialmente e extrajudicialmente, conduzindo-a de acordo com o seu Regimento Interno. ${ }^{45}$

O "Conselho Consultivo" é formado por trinta e dois membros, sendo dezesseis oriundos do Bundestag e dezesseis do Bundesrat, todos nomeados pelo Governo Federal, de acordo com as indicações das suas casas de origem. ${ }^{46}$ Dentre as matérias que se submetem à análise do "Conselho Consultivo", estão aquelas relacionadas ao leilão de licenças que envolvam radiofrequências escassas e as que dizem respeito ao provimento do serviço universal. ${ }^{47} \mathrm{~A}$ grande maioria das decisões, todavia, não é tomada pelo Beirat, que, como seu próprio nome diz, é um órgão de aconselhamento. $\mathrm{O}$

http://www.bundesnetzagentur.de/enid/d30ccb2d0cbf92cb14dcb40a7510648b,0/Die Bundesnetzagentur/Ueber_die_Agentur_sa.html (consultado em 26/02/2009). 45 Gesetz über die Bundesnetzagentur für Elektrizität, Gas, Telekommunikation, Post und Eisenbahnen/2005: “(1) Die Bundesnetzagentur wird von einem Präsidenten oder einer Präsidentin geleitet. Der Präsident oder die Präsidentin vertritt die Bundesnetzagentur gerichtlich und außergerichtlich und regelt die Verteilung und den Gang ihrer Geschäfte durch eine Geschäftsordnung. (2) Der Präsident oder die Präsidentin hat als ständige Vertretung zwei Vizepräsidenten oder Vizepräsidentinnen. (3) Der Präsident oder die Präsidentin und die zwei Vizepräsidenten oder Vizepräsidentinnen werden jeweils auf Vorschlag des Beirates von der Bundesregierung benannt. (4) Die Ernennung des Präsidenten oder der Präsidentin und der zwei Vizepräsidenten oder Vizepräsidentinnen erfolgt durch den Bundespräsidenten oder die Bundespräsidentin".

${ }^{46}$ Gesetz über die Bundesnetzagentur für Elektrizität, Gas, Telekommunikation, Post und Eisenbahnen/2005: "\$ 5 Beirat (1) Die Bundesnetzagentur hat einen Beirat, der aus jeweils 16 Mitgliedern des Deutschen Bundestages und 16 Vertretern oder Vertreterinnen des Bundesrates besteht; (...) Die Mitglieder des Beirates und die stellvertretenden Mitglieder werden jeweils auf Vorschlag des Deutschen Bundestages und des Bundesrates von der Bundesregierung berufen (...)”.

${ }^{47}$ Telekommunikatiosgesetz/2004: "\$ 116 Der Beirat nach \$ 5 des Gesetzes über die Bundesnetzagentur für Elektrizität, Gas, Telekommunikation, Post und Eisenbahnen hat folgende Aufgaben: (...) (3) Der Beirat ist berechtigt, Maßnahmen zur Umsetzung der Regulierungsziele und zur Sicherstellung des Universaldienstes zu beantragen. (6) Der Beirat ist bei der Aufstellung des Frequenznutzungsplanes nach $\S 54$ anzuhören".

Revista de Direito, Estado e Telecomunicações, v. 1, n. 1, p. 161-180 (2009)

DOI: https://doi.org/10.26512/lstr.vli1.21742 
"Conselho Consultivo" é regularmente informado sobre as atividades da Agência, para que possa expressar sua opinião.

As decisões da Bundesnetzagentur, que são publicadas como ato administrativo, se dão, em regra, por meio de "Câmaras de Decisão" (Beschlusskammern), cada uma delas especializada em determinada atividade $^{48}$, coordenadas por um presidente e dois vices. Em um primeiro momento, as competências das câmaras de decisão do RegTP referentes à telecomunicações foram perfeitamente reproduzidas na estrutura organizacional da Bundesnetzagentur. Cabia à Primeira Câmara de Decisão o licenciamento de serviços, entre eles o serviço universal, à Segunda a regulação de preços e tarifas, à Terceira o controle de práticas anticompetitivas e à Quarta o controle do acesso às redes e a interconexão entre operadoras. Atualmente, de acordo com o plano organizacional da agência ${ }^{49}$, as competências regulatórias relativas às telecomunicações foram concentradas nas $1^{\mathrm{a}}, 2^{\mathrm{a}}$ e $3^{\mathrm{a}}$ Câmaras de Decisão, sendo que a primeira Câmara foi transformada na "Câmara do Presidente", para a tomada de decisões sobre os temas previstos nos parágrafos 10 e seguintes da Lei de Telecomunicações, de 2004, entre eles, a definição e análise de mercados e os remédios regulatórios. Competem às demais Câmaras de Decisão $\left(4^{\mathrm{a}}, 5^{\mathrm{a}}\right.$, $6^{\mathrm{a}}, 7^{\mathrm{a}}, 8^{\mathrm{a}}$ e $9^{\mathrm{a}}$ ) a regulação dos mercados postal, elétrico e de gás.

${ }^{48}$ Telekommunikatiosgesetz/2004: “\$ 132 Die Regulierungsbehörde entscheidet durch Beschlusskammern in den Fällen des Teils 2, des § 55 Abs. 9, der \$§ 61, 62 und 81; Absatz 3 Satz 1 bleibt unberührt. Die Entscheidung ergeht durch Verwaltungsakt. (...)".

${ }^{49}$ Vigente desde 09/05/2008. Organizationsplan - Stand 09.05.2008. Bonn: Bundesnetzagentur [on line]. Disponível na internet via Disponível na internet via WWW.URL:

http://www.bundesnetzagentur.de/enid/40ff6e39fb43e2f7d0299e375a5fafb7,0/Ueber die_Agentur/Organisationsplan_sf.html (consultado em 26/02/2009). 


\section{FIGURA 1: Estrutura organizacional do $\operatorname{RegTP}$}

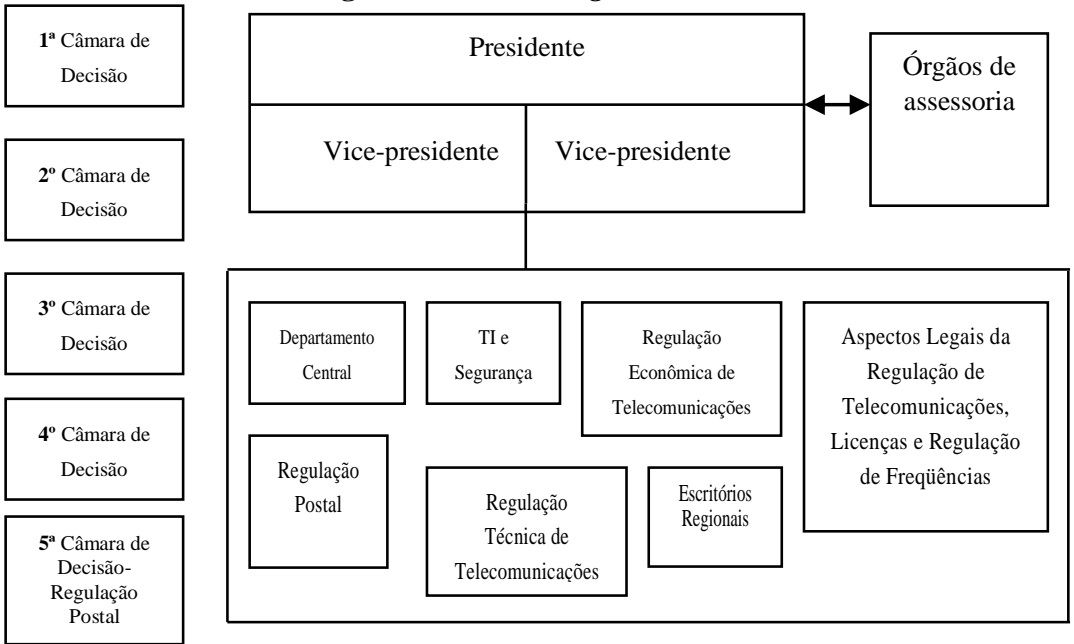

\section{FIGURA 2: Estrutura organizacional atual da Bundesnetzagentur ${ }^{50}$}

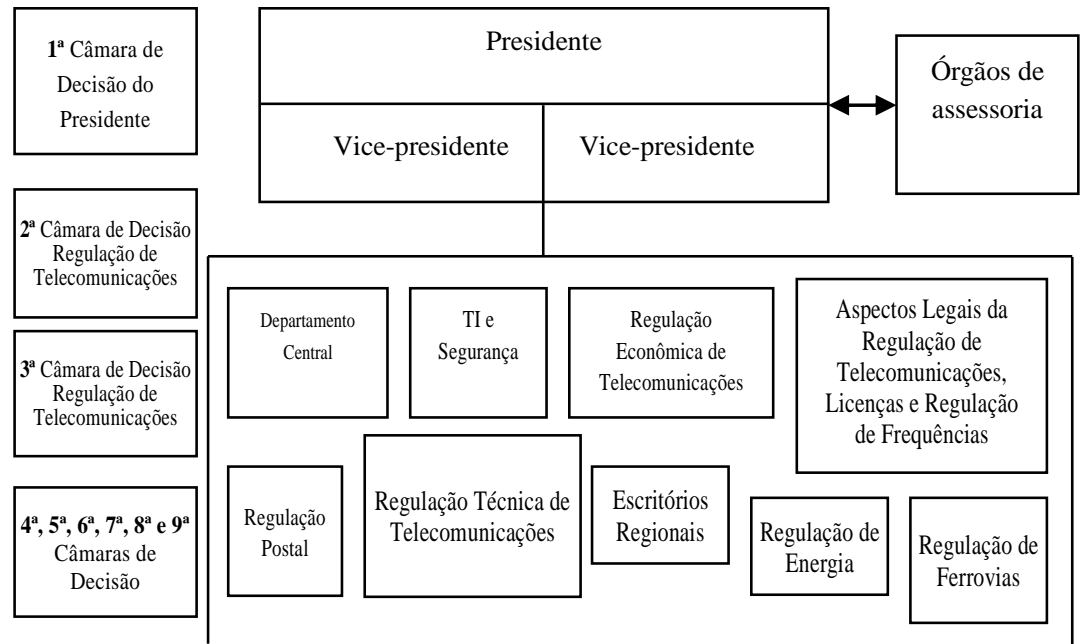

${ }^{50}$ Competem às outras Câmaras de Decisão $\left(4^{\mathrm{a}}, 5^{\mathrm{a}}, 6^{\mathrm{a}}, 7^{\mathrm{a}}, 8^{\mathrm{a}}\right.$ e $\left.9^{\mathrm{a}}\right)$ a regulação dos mercados postal, elétrico e de gás.

Revista de Direito, Estado e Telecomunicações, v. 1, n. 1, p. 161-180 (2009)

DOI: https://doi.org/10.26512/lstr.v1i1.21742 


\section{Conclusão}

As "Reformas Postais", ocorridas nos anos 80 e 90, e a edição da "Lei de Telecomunicações", em 2004, proporcionaram significativas transformações no setor de telecomunicações na Alemanha.

Todavia, o mesmo não pode ser dito em relação à criação da Bundesnetzagentur, em julho de 2005. Isto porque o surgimento desta "nova agência", se é que assim pode ser chamada (pelo menos no que toca ao setor de telecomunicações), se deu, principalmente, por motivos relacionados ao mercado energético deste país.

Dessarte, não fosse a necessidade de implantação de um órgão regulador para o setor de gás e eletricidade, o RegTP não teria sido renomeado, tampouco teria suas atribuições ampliadas.

A idéia central da transformação do RegTP em BundesnetzAgentur foi a de aproveitar a estrutura e a experiência adquirida pelo RegTP nos seus quase oito anos de existência e aplicá-la no monitoramento de outras áreas que possuem desafios regulatórios semelhantes, a saber: acesso à rede, bottlenecks, limites de capacidade, recursos escassos, entre outros.

E isto certamente poderia ter sido feito como o foi, pois, em que pese serem eletricidade, gás, telecomunicações, serviços postais e ferrovias infraestruturas bem distintas uma das outras, algumas em maior grau, outras em menor, todas elas consistem em indústrias de rede, sendo certo que a experiência, isto é, os sucessos e os insucessos adquiridos na regulação de um setor, são plenamente aproveitáveis na regulação de outras infraestruturas.

Tanto é que as atribuições e a estrutura organizacional do RegTP foram reproduzidas, em grande parte na Bundesnetzagentur, sendo que, em suma, o cenário regulatório do setor de telecomunicações na Alemanha, após o surgimento da Bundesnetzagentur, em termos práticos, não sofreu maiores modificações.

\section{Bibliografia}

ALEMANHA. Bundesnetzagentur. Aufgaben der Bundesnetzagentur. Bonn: Bundesnetzagentur. [on line] Disponível na internet via WWW.URL: 
http://www.bundesnetzagentur.de/enid/b9886b3b7b3ff01401b8069b523d1 f28,0/Ueber_die_Agentur/Aufgaben_30.html (consultado em 26/02/2009). ALEMANHA. Bundesnetzagentur. Status der Bundesnetzagentur. Bonn: Bundesnetzagentur. [on line] Disponível na internet via WWW.URL: http://www.bundesnetzagentur.de/enid/d30ccb2d0cbf92cb14dcb40a75106 48b,0/Die Bundesnetzagentur/Ueber_die Agentur_sa.html (consultado em 26/02/2009).

BRUNEKREEFT, Gert; TWELEMAN, Sven. Regulation, Competition and Investment in the German Eletricity Market: RegTP or REGTP. Cambridge: Cambridge Working Papers in Economics, 2004.

CHEN, Yung-chih, Die Liberalisierung der Telekommunikationsmärkte in Deutschland und das neue Konzept der Regulierung. Vol. 1, $1^{\mathrm{a}}$ ed., Berlin: Editora Rhombos, 2002.

DEUTSCHE WELLE. Monopólio encarece energia na Alemanha. Bonn: Deutsche Welle, 15.09.2004. [on line] Disponível na internet via WWW.URL: http://www.dwworld.de/dw/article/0,2144,1328713,00.html (consultado em 26/02/2009).

KNIEPS, Günter. Competition, Regulation and Privatisation: The Railroads and Telecommunications Network Industries in Germany. Freiburg: Discussion Paper - Institut für Verkehrswissenschaft und Regionalpolitik No. 104, 2004.

KOENIG, Christian; LOETZ, Sascha; NEUMANN, Andreas. Telekommunikationsrecht. Vol. I, $1^{\text {a }}$ ed., Heidelberg: Editora Recht und Wirtschaft, 2004.

Ofcomwatch. To be or not RegTP...London: Ofcomwatch, 01.08.2005.[on line] Disponível na internet via WWW.URL: http://www.ofcomwatch.co.uk/2005/08/to-be-or-not-regtp (consultado em 26/02/2009).

PICOT/Arnold. Das Telekommunikationsgesetz auf dem Prüfstand. Vol. I, $1^{a}$ ed. Berlin: Editora Springer, 2004.

PREVEZANOS, Klaudia. Sinal verde para maior concorrência. Bonn: Deutsche Welle, 04.09.2003. [on line] Disponível na internet via WWW.URL: http://www.dw-world.de/dw/article/0,2144,962672,00.html (consultado em 26/02/2009).

XAVIER, Patrick; YPSILANTI, Dimitri. Regulatory Reform In Germany. Paris, Publicações OECD, 2004. 